\title{
THE RESEARCH LAYOUT OF IMAGE CONTROL POINTS FOR 1:1000 B LEVEL DIGITAL ELEVATION MODEL PRODUCTION BASED ON UAV IN PLAIN AREA
}

\author{
Pengwei Xing ${ }^{1,2}$, Yifei Yang ${ }^{3}$, Shihua Tang ${ }^{1,2}$, Xi Zhang ${ }^{4}$, Yue Zhang ${ }^{1,2}$ \\ ${ }^{1}$ College of Geomatics and Geoinformation, Guilin University of Technology,No.319 Yan'shan Street, Guilin, Guangxi 541006, \\ China -xpw15033077108@163.com,634674209@qq.com \\ ${ }^{2}$ Guangxi Key Laboratory of Spatial Information and Geomatics, Guilin University of Technology, No.12 Jian'gan Road, Guilin, \\ Guangxi 541006, China \\ ${ }^{3}$ Geomatics Center of Guangxi, No.5 Jianzheng Road, Nanning, Guangxi 530023, China \\ ${ }^{4}$ School of Mining and Geomatics,Hebei University of Engineering, No.199 Guangming South Avenue, Handan, Hebei 056038, \\ China-1042952253@qq.com
}

\author{
Commission I, ICWG I/II
}

KEY WORDS: UAV Photogrammetry,Control Point,Root Meansquare Error of Elevation,Block Adjustment

\begin{abstract}
:
With the advent of the era of big data, traditional measurement techniques have been difficult to meet the information extraction required by contemporary measurement products, and light UAV (Unmanned Aerial Vehicles) was used to mapping is one of the development trends of aerial photogrammetry in China. When data is processed on aerial photography, the control points in the measurement area directly affect the accuracy of the later mapping results as the basis of mathematical calculation. However, the traditional aerial photogrammetry lays out the number of image control points according to a wide range of industry specifications, For example, lay Leveling control point at four corners + a row of elevation control points is lay at both ends of the area and lay Leveling control point at four corners + two vertical framed air routes at both ends of the zone (Zhang, J. Q., 2009),there are no specific method for the number of image control points to achieve a certain scale accuracy. As a result, there are too many or too few image control points in different topography and different scales. Measured by the error, image point density and reasonable layout of the data acquisition of the Trimble UX5 UAV, The causes of the errors are analyzed, and the precise data are obtained by comparing the experiments. Based on this, the relationship between changing the density of image control points and reasonable location is analyzed through the typical plain survey area of $0.718 \mathrm{~km}^{2}$. Designing four layout schemes of Image control points, taking the national standard as the standard, four groups of data are studied by comparing and analyzing GPS acquisition data with photogrammetry mapping data of Wuhan VISIONEK INC MapMatrix software. Through experimental analysis, the results show that the experimental data show that the light UAV can satisfy the production of 1:1000 B level digital elevation model in plain area when the image resolution is $350 \mathrm{dpi}$, the line height is controlled at $180 \pm 10 \mathrm{~m}$ and the density of image control point is more than $9 / \mathrm{km}^{2}$. At the same time, this image control point layout method is used reasonably can reduce the workload of the field, improve work efficiency, and also help to speed up the calculation of huge amount of aerial survey data so as to produce highprecision digital products.
\end{abstract}

\section{INTRODUCTION}

UAV photogrammetry technology has the advantages of low cost, high resolution and flexible operation. In recent years, with the development of UAV photogrammetry technology and the acceleration of urbanization in China, UAV has gradually penetrated into rescue, investigation, forensics and other fields. At present, there is no standard for the layout of image control points in large area UAV photogrammetry, which clearly points out how to arrange the number of points. IGI has proposed calibration field designing with six control points on the ground in the case of two consecutive contra-directional flights, each with 11 aerial photographs. IGI also provided software solution of AEROoffice+Bingo30 for calibration field; Applanix company first proposed control point layout of continuous flight which two routes plus 6-8 control points, or four routes plus 10-15 control points (Li, X. Y., 2005). Aiming at the problem of the number and distribution of image control points in 1:1000 digital elevation model aerial survey in plain area. This paper proposes a new improved layout method based on regional network layout scheme. The layout scheme of control points which can satisfy the accuracy of large-scale mapping was summarized. To solve the problem of too much or too little image control points in a large area and reduce the workload in the field. The new improved layout method not only ensures the accuracy of aerial survey products, but also effectively controls the number of image control points.

\section{ANALYSIS AND ELIMINATION OF PHOTOGRAMMETRIC ERROR OF UAV}

\subsection{Error Analysis of Photogrammetry for UAV}

1) Camera aberration

At present, the sensor on board the aircraft is a CCD nonmeasurement digital camera. Due to the existence of non-

\footnotetext{
* Corresponding author: Yifei Yang,Email: xpw15033077108@163.com
} 
square factor and non orthogonality and distortion of the photosensitive unit, There is a great distortion in the aerial photograph obtained by the camera after reinforcement. The existence of distortion makes the photogrammetry results unable to meet the accuracy requirements. (Cheng, X. J., 2002)

\section{2) Accuracy of stab control point}

Due to the small size of the fixed wing UAV, control points is relatively small. Therefore, it is difficult to find clear and thorny objects in aerial photographs, especially in wilderness areas. For the staff who are not skilled in manual spinning, it is impossible to accurately cut the control points, resulting in the result that the median error of the pins is greater than $20-50 \mu m$ (Li, D. R., 1986). So Whether the image control points are obvious, whether the laying is reasonable, whether the image contrast is ideal, and the staff's judgment of the image control point are all factors that restrict the accuracy of stab control points.

3) Flight attitude

Due to the uncontrollability and uncertainty of external factors such as climate, weather conditions will affect the flight attitude and image quality of UAV. The instability of flight attitude will lead to the three external azimuth elements (Omega, Kappa, Phi) large and irregular, the disordered and irregular image size and poor image quality. It directly causes the number of connection points to be extracted in relative orientation, and affects the accuracy of the results. (CH/Z30032010).

4) Accuracy of homonymous point matching

The basic principle of homonymous image point matching is to extract the connection points according the gray value of the feature points and the surrounding points of the adjacent image pairs. Low precision of connection point extraction will affect the calculation of relative orientation elements and exterior orientation elements (Wang, S. H., 2012); Too high precision of connection point extraction will lead to more iterations and lower data processing efficiency.

\subsection{Comparing and collecting high quality data to eliminate errors}

2.2.1 Controlling Camera Distortion Parameters: Due to the different lens distortion parameters, it is necessary to measure the camera distortion parameters (Xu, X. C., 2017).Therefore, when editing camera files to input camera parameters, for the first time, camera parameters are input on the basis of no distortion difference of aerial photographs, such as principal coordinate translation $(x, y)$,radial distortion coefficient $k_{1}, k_{2}, k_{3}$ eccentric distortion difference $p_{1}=0, p_{2}=0$; For the second time, the camera parameters are input based on the aberration of aerial photographs, and the corresponding image principal point translation and distortion coefficient are input according to the results of "easy-to-check". By comparing the accuracy of orthophoto images obtained by two different camera parameters, the effect of camera distortion on the accuracy of orthophoto images is verified, as shown in Figure 1.

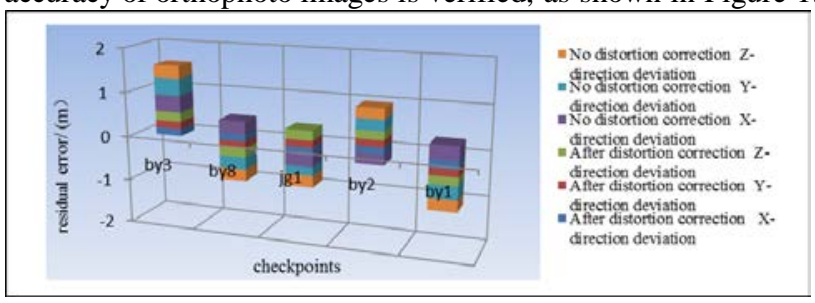

Figure 1. Camera distortion parameters affect data accuracy cylindrical diagram

2.2.2 Improving the Accuracy of Puncture Points: Choose a staff $\mathrm{A}$ who is not familiar with the process of thorn point and a worker $\mathrm{B}$ who is familiar with the process of thorn point Bn comparison, the error of the point accuracy of $\mathrm{A}$ is large and random. The error of the point accuracy of B is small. The effect of the point accuracy on the accuracy of orthophoto Image is verified by comparing the adjustment report results under different accuracy of the point, as shown in Figure 2.

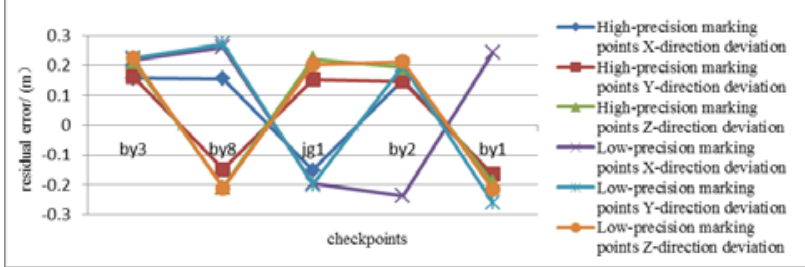

Figure 2. line chart of data residual error

2.2.3 Control Flight Attitude: Because the wind speed of the first sortie was a gale on the day of aerial survey, the three angle elements in pose data changed greatly; the second sortie was a breeze on the day of aerial survey, and the three angle elements in pose data were relatively stable, as shown in Tables 1 and Figure 3.

\begin{tabular}{cccc}
\hline Flight sortie & $\begin{array}{c}\text { Omega } \\
\text { variance }\end{array}$ & $\begin{array}{c}\text { Kappa } \\
\text { variance }\end{array}$ & $\begin{array}{c}\text { Phi } \\
\text { variance }\end{array}$ \\
\hline First sortie & 15.639 & 7.627 & 8.554 \\
Second sorties & 5.17 & 5.568 & 1.374 \\
\hline
\end{tabular}

Table 1. Variance of Pose parameters for two sorties 


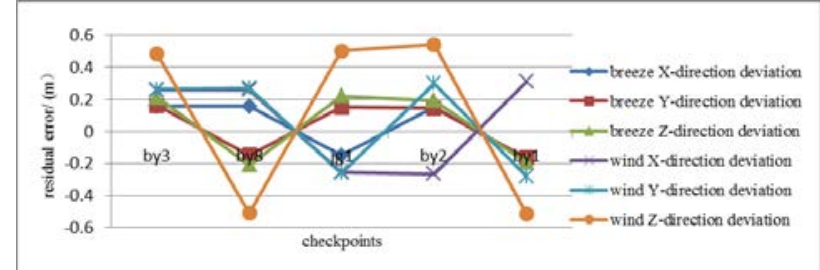

Figure 3. Flight attitude influencing data accuracy broken line diagram

2.2.4 Accuracy of homonymous point matching: The basic principle of point matching is to compare the gray values of the feature points and their surrounding points of adjacent images, and extract the feature points with the same gray values as the connection points of two photos (Min, T., 2013). Different methods of connection point extraction are used to verify the effect of connection point extraction accuracy on Orthophoto Image through two times of connection point accuracy. sa shown in Tables 2 and Figure 4.

\begin{tabular}{ccc}
\hline $\begin{array}{c}\text { Standard } \\
\text { deviation }\end{array}$ & $\begin{array}{c}\text { High Precision } \\
\text { Connection Point } /(\mu \mathrm{m})\end{array}$ & $\begin{array}{c}\text { Low Precision Connection } \\
\text { Points/ }(\mu \mathrm{m})\end{array}$ \\
\hline $\begin{array}{c}\text { X Standard } \\
\text { deviation }\end{array}$ & 22.3 & 15889.7 \\
$\begin{array}{c}\text { Y Standard } \\
\text { deviation }\end{array}$ & 5.5 & 31107 \\
$\begin{array}{c}\text { Mean square } \\
\text { error of a } \\
\text { point }\end{array}$ & 5.3 & 37.1 \\
\hline
\end{tabular}

Table 2. Comparison of accuracy of different connection points extraction

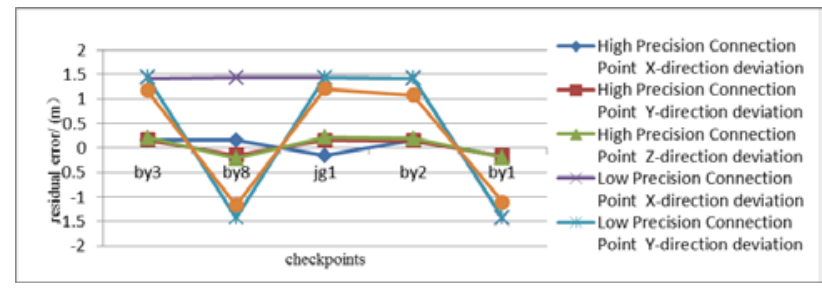

Figure 4 . The matching accuracy affects the data accuracy broken line diagram

Through the above data, it is proved that the accuracy of the data after solution can be improved by the scheme of accuracy of stab control point, stable flight attitude, extracting high precision connection points and controlling distortion parameters in conjunction with the image null point layout scheme.

\section{SURVEY AREA SURVEY AND IMAGE EMPTY POINT LAYOUT SCHEME}

\subsection{Research Flow of Image Control Point Layout Method}

Before confirming the research plan, the research plan is put forward on the basis of ensuring that the above four errors have been reduced, as shown in Figure. 5.

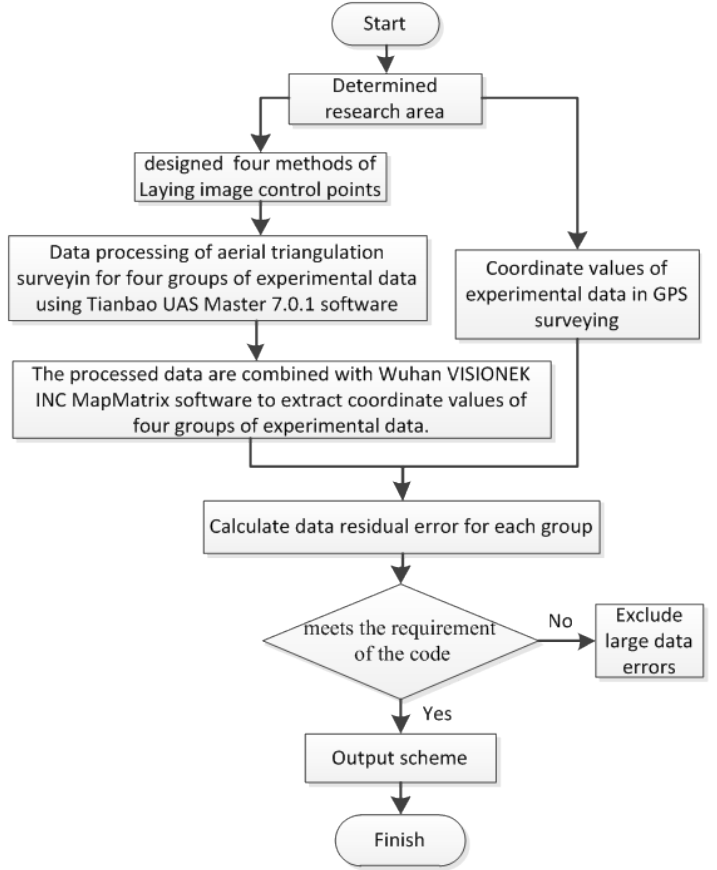

Figure 5. Flow chart of lay Leveling control point at four corners + Interlaced and evenly distributed elevation control points of the zone

\subsection{Survey area}

The research area is located in Houyaozhuang Village, Guantao County, Handan City. The survey area has a flat terrain with an area of $0.718 \mathrm{~km}^{2}$. The day of aerial survey was a breeze. The aerial altitude is $180+10 \mathrm{~m}$. The ground resolution is $4.70 \mathrm{~cm}$. The overlap rate of heading and sideway is $80 \%$. A total of 20 airstrips

\subsection{Image Control Point Layout Scheme}

The scheme is based on reducing the above four errors, four schemes are determined for the sparse layout of image control points in the field. Figure. 6 (a) scheme I : 4 control points, 1 control point in each corner of the measuring area; Figure. 6 (b) scheme II : two row control points, three control points on the left and three control points on the right, totally 6 control points; Figure. 6 (c) scheme III: three row control points, three control points on the left, three control points on the right, and two control points in the middle, as shown in Figure. 7 (a) scheme IV: Each corner of the survey area has one control point and two points in the middle. The accuracy of checkpoints and encryption points is the main factor to evaluate the adjustment results of a survey area. Among them, scheme I, II and III are to compare the influence of the number of image control points on the accuracy of mapping, as shown in Figure 6; scheme II and IV are to compare the influence of the rationality of the position distribution of image control points on the accuracy of mapping. Figurer. 7: Scheme III and Scheme IV are designed to illustrate that the number of image control points is large, but the mapping accuracy is not necessarily high. 


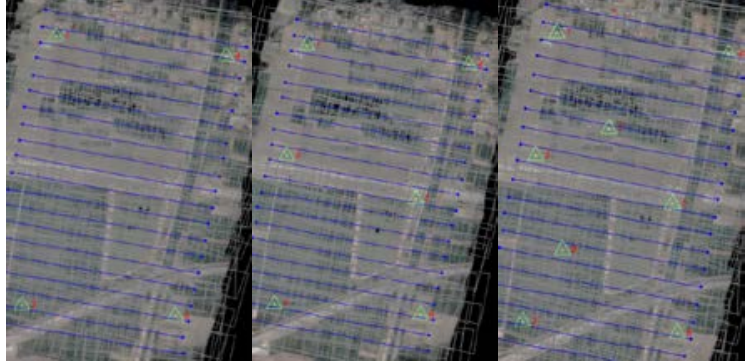

(a)

(b)

(c)

Figure 6. Number distribution map of different image control points in the same survey area

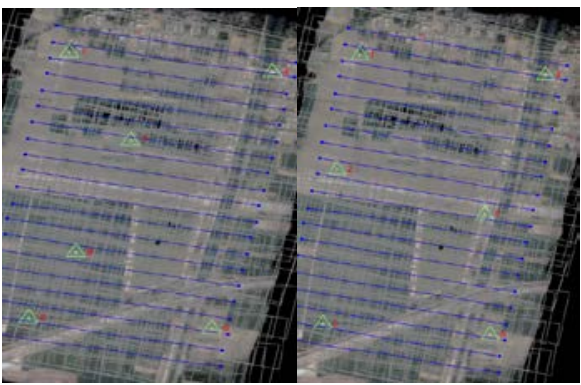

(a)

(b)

Figure 7. Number distribution map of different image control points in the same survey area

\section{NORMS AND INDICATORS REQUIREMENTS}

"Specifications for aerotriangulation of digital aerophotogrammetry” (GB/T 23236-2009), which stipulates the accuracy of regional network adjustment of $1: 1000$ topographic map as follows (see Table 3).

\begin{tabular}{cccc}
\hline $\begin{array}{c}\text { Drawing } \\
\text { scale }\end{array}$ & Category of points & $\begin{array}{c}\text { Plains horizontal } \\
\text { tolerance/m }\end{array}$ & $\begin{array}{c}\text { Plains elevation } \\
\text { tolerance/m }\end{array}$ \\
\hline \multirow{3}{*}{$1: 1000$} & $\begin{array}{c}\text { Basic orientation } \\
\text { point } \\
\text { checkpoint }\end{array}$ & 0.3 & 0.2 \\
& Common point & 0.5 & 0.28 \\
\hline
\end{tabular}

Table 3 Regional Network Evaluation Accuracy Specification Table

"Digital products of fundamental geographic information 1:500 1:1000 1:2000 digital elevation models" (CH/T 9008.22010)and " Digital products of fundamental geographic information 1:500 1:1000 1:2000 digital orthophoto maps " respectively(CH/T 9008.3-2010). The errors of obvious surface features in plain areas are stipulated in the following table(see Table 4).

\begin{tabular}{ccc}
\hline $\begin{array}{c}\text { Drawing } \\
\text { scale }\end{array}$ & $\begin{array}{c}\text { Mean square error of } \\
\text { height } / \mathrm{m}\end{array}$ & $\begin{array}{c}\text { Mean square error of plane } \\
/ \mathrm{m}\end{array}$ \\
\hline $1: 1000$ & 0.25 & 0.6 \\
\hline
\end{tabular}

Table 4 Obvious object accuracy specification table

Mean square error (MSE): The square root of the square median of a set of errors under the same observation conditions:

$$
\sigma= \pm \sqrt{\sum_{i=1}^{n} \frac{\Delta_{i}^{2}}{n-1}}
$$

formula (1)

Where:

$$
\sigma=\text { the error in checkpoint (unit: } \mathrm{m} \text { ) }
$$

$\Delta=$ the error between field measured value and settlement value of checkpoint (unit: $\mathrm{m}$ )

$\mathrm{n}=$ checkpoint participating in adjustment accuracy.

Define the image control point density formula:

$$
p=\frac{m}{s}
$$

Where :

$$
\begin{aligned}
& p=\text { the density of image control points (unit: } \mathrm{km}^{2} \text { ) } \\
& m=\text { the number of image control points } \\
& s=\text { the area of measurement area (unit: } \mathrm{km}^{2} \text { ) }
\end{aligned}
$$

\section{ANALYSIS OF THE INFLUENCE OF IMAGE CONTROL POINT LAYOUT SCHEME ON MAPPING ACCURACY}

\subsection{GPS/POS-Supported Aerial Triangulation Model}

Aerial triangulation is also called analytical aerial triangulation encryption. It is a process of determining all image exterior orientation elements in the area to be measured by photogrammetric analysis (Chen, D., 2017). GPS/POSsupported aerial triangulation is also called GNSS/IMU combined system (Yang, Y. X., 2016). It is a classical aerial triangulation method which can reduce the number of field control points nearly 1 / 2 (Xu, M., 2013) (Zhu, F., 2014). The basic idea is to determine the coordinates of image principal points and exterior orientation elements by integrating POS and GPS positioning system, so that the regional network adjustment of image point data and measurement control point data can be carried out under the condition of only a few ground control points. The coordinate systems involved include image coordinate system (o-xy), image-space coordinate system (S-xyz), image-space auxiliary coordinate system ( $S$ - $X Y Z$ ), photogrammetric coordinate system $\left(A-X_{p} Y_{p} Z_{p}\right)$ and objectspace coordinate system $\left(O-X_{t} Y_{t} Z_{t}\right)$.

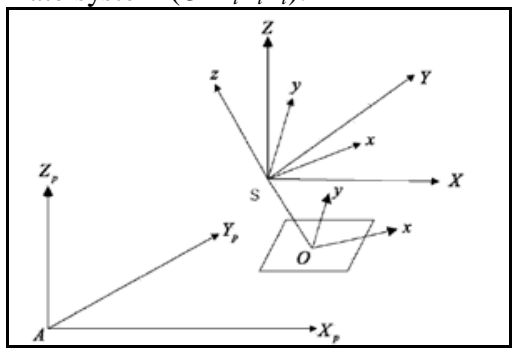

Figure 8. Photogrammetric coordinate system sketch In the model calculation, the orthogonal matrix $\mathrm{R}$ is determined by using the three angular elements of the six exterior orientation elements of the image $(\varphi, \omega, \kappa)$. The transformation between the image space coordinate system and the image space auxiliary coordinate system is carried out. $\mathrm{R}$ can be expressed as formula (3):

$R=R_{\varphi} R_{\omega} R_{\kappa}=\left[\begin{array}{ccc}\cos \varphi & 0 & -\sin \varphi \\ 0 & 1 & 0 \\ \sin \varphi & 0 & \cos \varphi\end{array}\right]\left[\begin{array}{ccc}1 & 0 & 0 \\ 0 & \cos \omega & -\sin \omega \\ 0 & \sin \omega & \cos \omega\end{array}\right]\left[\begin{array}{ccc}\cos \kappa & -\sin \kappa & 0 \\ \sin \kappa & \cos \kappa & 0 \\ 0 & 0 & 1\end{array}\right]$
$=\left[\begin{array}{ccc}\cos \varphi \cos \kappa-\sin \varphi \sin \omega \sin \kappa & -\cos \varphi \sin \kappa-\sin \varphi \sin \omega \cos \kappa & -\sin \varphi \cos \omega \\ \cos \omega \sin \kappa & \cos \omega \cos \kappa & -\sin \omega \\ \sin \varphi \cos \kappa+\cos \varphi \sin \omega \sin \kappa & -\sin \varphi \sin \kappa+\cos \varphi \sin \omega \cos \kappa & \cos \varphi \cos \omega\end{array}\right]$ formula (3)

Constructing the mathematical model of basic central projection is an important basis of aerial triangulation in photogrammetry, so as to solve the problems of space resection 
of single photo, two-image space intersection and bundle block adjustment (Yuan, X. X., 2000). The calculation is based on the measurement of a large number of image connection points and observation of a sufficient number of control points with high accuracy, and then on this basis, the self-calibration beam method regional network adjustment is carried out to obtain the relationship between the image-space auxiliary coordinate system and the object-space coordinate system. Formula (4): $\left.\begin{array}{l}x-x_{0}=-f \frac{a_{1}\left(X_{A}-X_{S}\right)+b_{1}\left(Y_{A}-Y_{S}\right)+c_{1}\left(Z_{A}-Z_{S}\right)}{a_{3}\left(X_{A}-X_{S}\right)+b_{3}\left(Y_{A}-Y_{S}\right)+c_{3}\left(Z_{A}-Z_{S}\right)} \\ y-y_{0}=-f \frac{a_{2}\left(X_{A}-X_{S}\right)+b_{2}\left(Y_{A}-Y_{S}\right)+c_{2}\left(Z_{A}-Z_{S}\right)}{a_{3}\left(X_{A}-X_{S}\right)+b_{3}\left(Y_{A}-Y_{S}\right)+c_{3}\left(Z_{A}-Z_{S}\right)}\end{array}\right\}$

Where:

Formula (4)

$x, y=$ the image plane coordinates of the image point $x_{0}, y_{0}, f=$ the internal orientation elements of the image

$X_{S}, \quad Y_{S}, \quad Z_{S}=$ the object-space coordinates of the photographic site;

$X_{A}, Y_{A}, Z_{A}=$ the object-space coordinates of the object points;

$a_{i}, b_{i}, c_{i}(\mathrm{i}=1,2,3)=$ the nine direction cosine of the three external azimuth elements of the image; adopted for control point puncture. The camera distortion parameters are calibrated and extracted by high-precision connection points, which are solved by aerial triangulation. The following is the data of GPS coordinate points as shown in Table 5, and the accuracy of the four experiments is shown in Table 6-9.

\begin{tabular}{cccc}
\hline \multirow{2}{*}{ Checkpoint number } & \multicolumn{3}{c}{ Coordinate data collected by GPS } \\
\cline { 2 - 4 } & $\mathrm{X} / \mathrm{m}$ & $\mathrm{Y} / \mathrm{m}$ & $\mathrm{Z} / \mathrm{m}$ \\
\hline by3 & 611939.804 & 4043411.441 & 41.569 \\
by8 & 612068.814 & 4043637.659 & 41.852 \\
jg1 & 611984.027 & 4043877.041 & 42.062 \\
by2 & 612424.113 & 4043846.259 & 42.62 \\
by1 & 612449.808 & 4043834.589 & 43.039 \\
kh1 & 612212.215 & 4043505.238 & 40.272 \\
kh2 & 612239.822 & 4043804.147 & 41.484 \\
syx & 612424.585 & 4043650.433 & 36.884 \\
k67 & 612476.738 & 4044029.493 & 42.656 \\
k12 & 612303.51 & 4044162.876 & 42.088 \\
k9 & 612067.249 & 4044175.259 & 41.185 \\
\hline
\end{tabular}

Table 5 GPS survey data

\subsection{Experimental data processing}

Trimble UAS Master 7.0.1 is the data processing software in the industry. Semi-automatic manual puncture method is

\begin{tabular}{|c|c|c|c|c|c|c|}
\hline \multirow[b]{2}{*}{ Checkpoint number } & \multicolumn{3}{|c|}{ Coordinate data extracted from UASmaster 7.0.1 and MapMatrix 5.0 software } & \multicolumn{3}{|c|}{ residual error } \\
\hline & $\mathrm{X} / \mathrm{m}$ & $\mathrm{Y} / \mathrm{m}$ & $\mathrm{Z} / \mathrm{m}$ & $\begin{array}{c}\mathrm{X} \\
\text { deviation/m }\end{array}$ & Y deviation/m & $\mathrm{Z}$ deviation/m \\
\hline by3 & 611940.058 & 4043411.686 & 41.823 & -0.254 & -0.245 & -0.254 \\
\hline by8 & 612069.070 & 4043637.391 & 41.594 & -0.256 & 0.268 & 0.258 \\
\hline jg1 & 611983.766 & 4043877.264 & 42.354 & 0.261 & -0.223 & -0.292 \\
\hline by2 & 612424.356 & 4043846.505 & 42.924 & -0.243 & -0.247 & -0.304 \\
\hline by1 & 612449.535 & 4043834.305 & 42.748 & 0.273 & 0.284 & 0.291 \\
\hline kh1 & 612212.457 & 4043505.460 & 40.539 & -0.242 & -0.222 & -0.267 \\
\hline kh2 & 612240.079 & 4043804.395 & 41.213 & -0.257 & -0.248 & 0.271 \\
\hline syx & 612424.332 & 4043650.188 & 37.174 & 0.253 & 0.245 & -0.290 \\
\hline k67 & 612477.000 & 4044029.775 & 42.958 & -0.262 & -0.282 & -0.302 \\
\hline k12 & 612303.775 & 4044162.613 & 41.835 & -0.265 & 0.263 & 0.253 \\
\hline k9 & 612067.520 & 4044175.530 & 41.478 & -0.271 & -0.271 & -0.293 \\
\hline
\end{tabular}

Table 6 Scheme I experimental data

\begin{tabular}{|c|c|c|c|c|c|c|}
\hline \multirow{2}{*}{$\begin{array}{l}\text { Checkpoint } \\
\text { number }\end{array}$} & \multicolumn{3}{|c|}{ Coordinate data extracted from UASmaster 7.0.1 and MapMatrix 5.0 software } & \multicolumn{3}{|c|}{ residual error } \\
\hline & $\mathrm{X} / \mathrm{m}$ & $\mathrm{Y} / \mathrm{m}$ & $\mathrm{Z} / \mathrm{m}$ & $\mathrm{X}$ deviation $/ \mathrm{m}$ & $\mathrm{Y}$ deviation $/ \mathrm{m}$ & $\mathrm{Z}$ deviation $/ \mathrm{m}$ \\
\hline by3 & 611940.012 & 4043411.645 & 41.824 & -0.208 & -0.204 & -0.255 \\
\hline by8 & 612069.025 & 4043637.871 & 41.611 & -0.211 & -0.212 & 0.241 \\
\hline jg1 & 611983.823 & 4043876.843 & 42.326 & 0.204 & 0.198 & -0.264 \\
\hline by2 & 612423.900 & 4043846.479 & 42.893 & 0.213 & -0.221 & -0.273 \\
\hline by1 & 612450.020 & 4043834.370 & 42.805 & -0.212 & 0.219 & 0.234 \\
\hline kh1 & 612212.424 & 4043505.023 & 40.503 & -0.209 & 0.215 & -0.231 \\
\hline kh2 & 612240.032 & 4043804.365 & 41.736 & -0.210 & -0.218 & -0.252 \\
\hline syx & 612424.378 & 4043650.649 & 36.621 & 0.207 & -0.216 & 0.263 \\
\hline k67 & 612476.947 & 4044029.690 & 42.903 & -0.209 & -0.197 & -0.247 \\
\hline k12 & 612303.722 & 4044162.680 & 42.350 & -0.212 & 0.196 & -0.262 \\
\hline k9 & 612067.447 & 4044175.480 & 41.455 & -0.198 & -0.221 & -0.270 \\
\hline
\end{tabular}

Table 7 Scheme II experimental data

\begin{tabular}{|c|c|c|c|c|c|c|}
\hline \multirow{2}{*}{$\begin{array}{c}\text { Checkpoint } \\
\text { number }\end{array}$} & \multicolumn{3}{|c|}{ Coordinate data extracted from UASmaster 7.0.1 and MapMatrix 5.0 software } & \multicolumn{3}{|c|}{ residual error } \\
\hline & $\mathrm{X} / \mathrm{m}$ & $\mathrm{Y} / \mathrm{m}$ & $\mathrm{Z} / \mathrm{m}$ & $\mathrm{X}$ deviation/m & Y deviation/m & $\mathrm{Z}$ deviation/m \\
\hline by3 & 611939.962 & 4043411.605 & 41.783 & -0.158 & -0.164 & -0.214 \\
\hline by8 & 612068.970 & 4043637.511 & 41.644 & -0.156 & 0.148 & 0.208 \\
\hline jg1 & 611983.876 & 4043877.194 & 42.284 & 0.151 & -0.153 & -0.222 \\
\hline
\end{tabular}




\begin{tabular}{cccccccc} 
by2 & 612424.266 & 4043846.405 & 42.814 & -0.153 & -0.147 & -0.194 \\
by1 & 612449.635 & 4043834.425 & 42.848 & 0.173 & 0.164 & 0.191 \\
kh1 & 612212.380 & 4043505.398 & 40.473 & -0.165 & -0.160 & -0.201 \\
kh2 & 612239.991 & 4043804.303 & 41.286 & -0.169 & -0.156 & 0.198 \\
syx & 612424.742 & 4043650.285 & 37.071 & -0.157 & 0.148 & -0.187 \\
k67 & 612476.910 & 4044029.65 & 42.829 & -0.172 & -0.157 & -0.173 \\
k12 & 612303.356 & 4044163.041 & 42.266 & 0.154 & -0.165 & -0.178 \\
k9 & 612067.400 & 4044175.427 & 41.395 & -0.151 & -0.168 & -0.210 \\
\hline
\end{tabular}

Table 8. Scheme III experimental data

\begin{tabular}{|c|c|c|c|c|c|c|}
\hline \multirow{2}{*}{$\begin{array}{l}\text { Checkpoint } \\
\text { number }\end{array}$} & \multicolumn{3}{|c|}{ Coordinate data extracted from UASmaster 7.0.1 and MapMatrix 5.0 software } & \multicolumn{3}{|c|}{ residual error } \\
\hline & $\mathrm{X} / \mathrm{m}$ & $\mathrm{Y} / \mathrm{m}$ & $\mathrm{Z} / \mathrm{m}$ & $\mathrm{X}$ deviation $/ \mathrm{m}$ & $\mathrm{Y}$ deviation/m & $\mathrm{Z}$ deviation $/ \mathrm{m}$ \\
\hline by3 & 611939.952 & 4043411.595 & 41.773 & -0.148 & -0.154 & -0.204 \\
\hline by8 & 612068.990 & 4043637.491 & 41.644 & -0.176 & 0.168 & 0.208 \\
\hline jg1 & 611983.875 & 4043877.194 & 42.289 & 0.152 & -0.153 & -0.227 \\
\hline by2 & 612424.256 & 4043846.409 & 42.824 & -0.143 & -0.151 & -0.204 \\
\hline by1 & 612449.991 & 4043834.415 & 43.210 & -0.183 & 0.174 & -0.171 \\
\hline kh1 & 612212.069 & 4043505.390 & 40.103 & 0.146 & -0.152 & 0.169 \\
\hline kh2 & 612239.978 & 4043804.296 & 41.656 & -0.156 & -0.149 & -0.172 \\
\hline syx & 612424.417 & 4043650.590 & 37.085 & 0.168 & -0.157 & -0.201 \\
\hline k67 & 612476.588 & 4044029.329 & 42.841 & 0.150 & 0.164 & -0.185 \\
\hline k12 & 612303.655 & 4044163.030 & 41.913 & -0.145 & -0.154 & 0.175 \\
\hline k9 & 612067.409 & 4044175.417 & 41.358 & -0.160 & -0.158 & -0.173 \\
\hline
\end{tabular}

Table 9. Scheme IV experimental data

\subsection{Accuracy analysis of experimental data}

The coordinate data of GPS measurement was taken as the true value when analyzing the influence of four groups of image control point schemes on the mapping accuracy. Taken the corresponding coordinates of the four sets of experimental data, the deviation of these coordinates $\mathrm{x}, \mathrm{y}$ and $\mathrm{z}$ direction was taken as an indicator of the accuracy of the evaluation results. In order to analyse the data more clearly, the residual error values in $\mathrm{X}, \mathrm{Y}$ and $\mathrm{Z}$ directions was taken as absolute values to generate a polyline map. The results are shown in Figure 9-11.

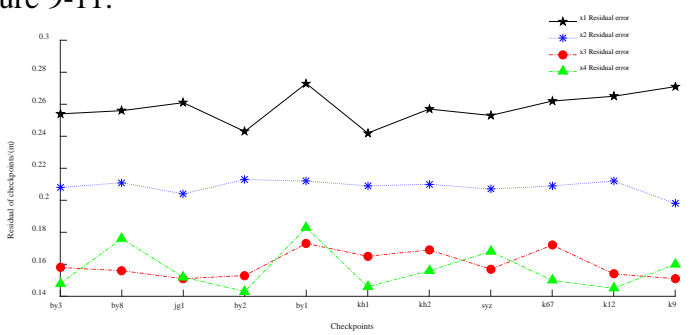

Figure 9. Contrast analysis diagram of Xdirection residual trend

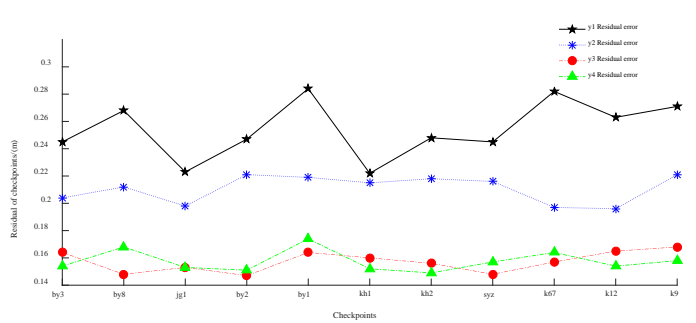

Figure 10. Contrast analysis diagram of Ydirection residual trend

From Figure 9 and Figure 10, it can be seen that the absolute value of the residual error between the observation value and the true value of the traditional image control point layout scheme $\mathrm{I}$ is larger, and the deviations of $\mathrm{x} 1$ and $\mathrm{y} 1$ are all floating around $0.25 \mathrm{~m}$. With the increasing number of image control points in scheme II, scheme III and scheme IV, the data accuracy is gradually improved, and the deviations of $\mathrm{x} 2$ and $\mathrm{y} 2$ are floating around $0.2 \mathrm{~m}$. The deviations of $\mathrm{x} 3, \mathrm{y} 3, \mathrm{x} 4$ and $\mathrm{y} 4$ all fluctuate around $0.15 \mathrm{~m}$. It can be seen that the method of lay levelling control point at four corners + Interlaced and evenly distributed elevation control points of the zone has a slightly higher accuracy and the data floating tends to be stable.

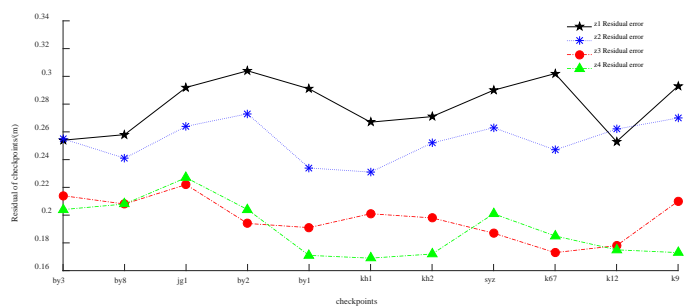

Figure 11. Contrast analysis diagram of Zdirection residual trend

As can be seen from Figure 11, the $\mathrm{z} 1$ in scheme I does not meet the requirement of mean square error of height less than $0.25 \mathrm{~m}$ in the specification. Accordingly, scheme II is excluded. The $\mathrm{z} 3$ in scheme III can meet the specification, but its accuracy is slightly lower than that in scheme IV.

According to the above analysis, using the image control point layout method proposed in this paper, elevation points are automatically extracted from the calculated data and then artificial extracted elevation points which were not affected by vegetation and environmental factors. Finally, these points and topographic maps are imported into the WuHan VISIONEK INC software, generating a high Precision Digital Elevation Model. As shown in Figures 12 (a) and 12 (b) . 


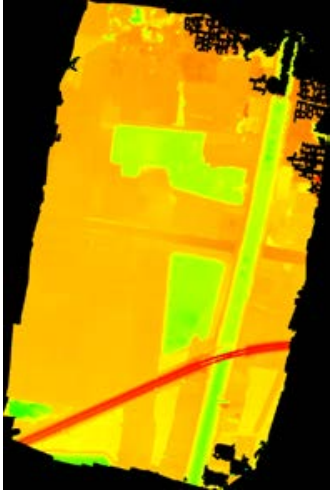

(a)

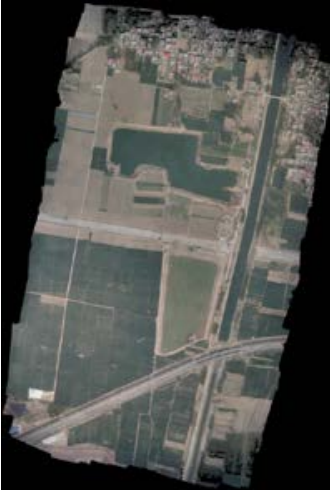

(b)
Figure 12. Digital Elevation Matrix and Digital Orthophoto Map

By comparing the schemes I, II and III, we can see that the mapping accuracy will be improved to a certain extent with the increase of image control points. When the number of image control points are 8 (image control point density $p=11.14 / \mathrm{km}^{2}$ ), it meets the requirements of the specification: the mean square error of height is less than $0.25 \mathrm{~m}$; By comparing scheme II and scheme IV, we can see that under the condition of the same number of image control points, scheme IV has met the intermediate error of 1:1000 B Level Digital Elevation Model under the premise of six image control points (image control point density $\mathrm{p}=8.36 / \mathrm{km}^{2}$ ). Therefore, the rationality of the distribution of image control points has an impact on the accuracy of mapping. By comparing scheme III and scheme IV, it can be concluded that under the premise of meeting the accuracy, the image control points of field measurement can be reduced to meet the requirements of grade specifications.

\section{CONCLUSION}

This paper discusses the accuracy of 1:1000 B level digital elevation model and the layout of image control points in plain area based on light UAV. The analysis of the measured data shows that, On the premise of eliminating the pinpoint error, guaranteeing the accuracy of camera distortion parameters, flight attitude stability and guaranteeing high accuracy of connection points extraction, etc. the number of image control points of $1 \mathrm{~km} 2$ should be more than 9 . According to the size of the survey area, the image control point location should be reasonably selected by using the method of "quadrangular levelling control point + staggered uniform elevation point in the region", so that the mapping accuracy of 1:1000 B level digital elevation model plain area can be achieved. This method can reduce the workload of field work, improve work efficiency and produce high-precision digital products.

\section{REFERENCES}

Zhang, J. Q., Pan, L., Wang, S.Y., 2009: Photogrammetry 2nd Edition[M]. Wuhan University Press, 2009:103-104.

Li, X. Y., 2005: IMU/DGPS-supported Photogrammetry Theory,Approaches and Practice[D]. Information Engineering University, 2005.
Cheng, X. J., Hu, M. J., 2002: The Determination of Digital Camera's Distortion[J]. Acta Geodaetica Et Cartographic Sinica, 2002.

Li, D. R., 1986:Error Processing of Photogrammetric Adjustment System Lecture 3 Talking about the spine of the connecting point of the picture- - The Key to Reduce the Accidental Error of Image Point Coordinates[J]. Bulletin of Surveying and Mapping, 1986(3).

CH/Z3003-2010: State Bureau of Surveying and Mapping.Specifications for field work of low-altitude digital aerophotogrammetry[M]. The Mapping Publishing Company, 2010.

Wang, S. H., You, H. J., Fu,J., 2012: An Automatic Method for Finding Matches in SAR Images Based on Coarser Scale Bilateral Filtering SIFT[J]. Journal of Electronics \& Information Technology, 2012, 34(2):287-293.

Xu, X. C., Xu, A. G., Ma, l., et al, 2017: The Influence of Lens Distortion Parameters on Measurement Accuracy of Image Points in Aerial Photogrammetry[J]. Bulletin of Surveying and Mapping, 2017.

Min, T., Yong, S. L., Xin, L., et al, 2013:Local enhancement method and its applications to UAV image matching[J]. Remote Sensing for Land \& Resources, 2013, 25(04):53-57.

GB/T 23236-2009: Specifications for aerotriangulation of digital aerophotogrammetry[S]. Standards Press of China, 2009.

CH/T 9008.2-2010: Digital products of fundamental geographic information 1:500 1:1000 1:2000 digital elevation models[S], Surveying and Mapping Publishing House, 2010. CH/T 9008.3-2010: Digital products of fundamental geographic information 1:500 1:1000 1:2000 digital orthophoto maps[S], Surveying and Mapping Publishing House, 2010.

Chen, D., Lin, H., Su, T. L., et al. 2017: UAV Aerial Triangulation for Low-attitude Photogrammetry Assisted by Multi-view Geometry Theory[J]. Bulletin of Surveying \& Mapping, 2017.

Yang, Y. X., 2016: Study of IMU/GPS Composed Navigation System for Shipboard UAV[J]. Ship Electronic Engineering, 2016.

Xu, M., Zhu, Y., Zhang, X. Z., 2013: The Influence Factors of GPS/IMU Supported Aerial Triangulation Accuracy Analysis Based on SSK Software[J]. Geomatics \& Spatial Information Technology, 2013.

Zhu, F., Xiao, H., Wei, Y. N., 2014:Summary of UAV remote sensing image mosaicking technology[J]. Computer Engineering and Applications, 2014.

Yuan, X. X., 2000: Principle, software and experiment of GPS-supported aerotriangulation[J]. Geo-Spatial Information Science, 2000, 3(1):24-33. 